TRANSBOUNDARY AIR POLLUTION IN EUROPE:

AN INTERACTIVE MULTICRITERIA TRADEOFF ANALYSIS

Antonie Stam

Department of Management Sciences and Information

Technology, College of Business Administration,

University of Georgia, Athens, USA

Markku Kuula

Helsinki School of Economics, Helsinki, Finland

Herman Cesar

Department of Economics, European University Institute, Florence, Italy

RR-93-4

February 1993

Reprinted from European Journal of Operational Research (1992) 56(2):263-277. 
Research Reports, which record research conducted at IIASA, are independently reviewed before publication. Views or opinions expressed herein do not necessarily represent those of the Institute, its National Member Organizations, or other organizations supporting the work.

Reprinted with permission from European Journal of Operational Research (1992) 56(2): 263-277.

Copyright (C)1992 Elsevier Science Publishers B.V.

All rights reserved. No part of this publication may be reproduced or transmitted in any form or by any means, electronic or mechanical, including photocopy, recording, or any information storage or retrieval system, without permission in writing from the copyright holder.

Printed by Novographic, Vienna, Austria. 


\section{Foreword}

Over the years IIASA has played an important role in developing methods for improving decision making concerning the acid rain problem. IIASA's RAINS model is accepted as a basis for negotiations between countries with regard to the abatement of acid rain. As a decision problem, the abatement of acid rain is typically a problem with several criteria, for example, the amounts of money spent by the different countries to diminish emissions and the target levels for the depositions. This paper proposes an interactive approach for finding reasonable deposition levels for all countries involved by a limited transfer of funds between those countries.

The basis for this work was laid when the authors participated in IIASA's Young Scientist Summer Program. The work is a result of cooperation between the Transboundary Air Pollution Project and the Methodology Decision Analysis Project.

JAAP WESSELS

Leader

Methodology Decision Analysis Project 


\title{
Transboundary air pollution in Europe: An interactive multicriteria tradeoff analysis
}

\author{
Antonie Stam \\ Department of Management Sciences and Information Technology, College of Business Administration, \\ University of Georgia, Athens, GA 30602, USA
}

Markku Kuula

Helsinki School of Economics, Runeberginkatu 14-16, SF-00100 Helsinki, Finland

\section{Herman Cesar}

Department of Economics, European University Institute, Via dei Rocettini 9, San Domenico di Fiesole, I-50016, Florence, Italy

\section{Received March 1990}

\begin{abstract}
In this paper, the acid rain problem in Europe is discussed, stressing the transboundary tradeoffs between abatement costs of sulphur emission reduction and corresponding deposition levels in the different countries. An interactive decision support methodology is proposed which utilizes a powerful nonlinear multicriteria software package to evaluate various scenarios and tradeoffs. This methodology provides a more appropriate tool for policy making than single-objective minimization of costs with given target deposition levels, because in the latter the tradeoffs cannot be analyzed directly. The results from a tradeoff analysis using previously published data suggest that reasonable deposition levels can be reached with limited transfers of funds between countries. The extent of these transfers can be controlled by selecting appropriate target levels for the criteria across countries.
\end{abstract}

Keywords: Multicriteria decision making, nonlinear optimization, environmental analysis, international policy making

\section{Introduction}

Nowadays, acid rain is one of the major environmental concerns in Europe. Yet, as many other problems, the problem of acid rain is not new. Over 300 years ago, the English nobleman John Evelyn presented an essay titled "Fugifugium or the Inconvenience of the Aer and Smoake of London Dissipated, together with some Remedies Humbly Proposed", to King Charles II (Evelyn, 1661). Evelyn already suggested the theory that sulphur originating from smoke caused by burning coal turns silver black and destroys iron and stone. In the following centuries the awareness of this problem has grown, and more and more has been done to avoid the negative impacts of pollution, especially at the local and regional level. Recently it has been established that both sulphur dioxide $\left(\mathrm{SO}_{2}\right)$ and nitrogen oxide $\left(\mathrm{NO}_{x}\right)$ emissions contribute to the forming of acid rain.

Over the last few decades the scale of environmental problems has shifted dramatically from the local and regional level to a continental (acid rain) and global (greenhouse effect) level. The primary reason for this shift is the fact that the problem has now become transboundary, in that emissions in one country affect the environmental quality in other countries, and at the same time the environmental quality in a given country is affected by emissions in other countries.

In this paper the focus is on acid rain in 
Europe, and more specifically on the transboundary problem of tradeoffs between and balancing of costs and benefits of abatement policies across countries in Europe. The costs of emission reduction consist of the expenses associated with abating air pollution originating from $\mathrm{SO}_{2}$ and $\mathrm{NO}_{x}$. Power plants, oil refineries and other industries, as well as transportation and the domestic sector are to a large extent responsible for these emissions. The benefits of abatement measures include decreased damage to materials, buildings and ecosystems, particularly forests and aquatic systems, as well as human health.

For several reasons it is difficult to balance costs and benefits of emission reduction. The first reason is that costs and benefits may not accrue to the same country, so that the acid rain prob- lem calls for international environmental policies and negotiations in order to determine how much each country should abate and how much each country should pay for abatement in other countries. The second reason complicating the analysis is that benefits cannot easily be expressed in terms of monetary figures, so that preferably a comparison of costs and benefits would involve direct tradeoffs in relevant physical units.

The purpose of our paper is to gain insight in the decision dynamics of this complicated problem by exploring the nature of tradeoffs between the abatement costs incurred by each country and deposition levels throughout Europe. In order to analyze this issue we utilize a simplified version of RAINS (Regional Acidification Information and Simulation) (Alcamo et al., 1987), an inte-

Table 1

Relevant information on the 27 European countries ${ }^{\text {a,b }}$

\begin{tabular}{|c|c|c|c|c|c|c|c|}
\hline \multirow{2}{*}{$\begin{array}{l}\text { Country name } \\
i\end{array}$} & \multirow[t]{2}{*}{ Abbreviation } & \multirow{2}{*}{$\begin{array}{l}\text { Current } \\
\text { emissions } \\
\text { (1000 tons) } \\
e_{i}\end{array}$} & \multirow{2}{*}{$\begin{array}{l}\text { Maximum } \\
\text { reduction } \\
(\%) \\
m_{i}\end{array}$} & \multirow{2}{*}{$\begin{array}{l}1980 \text { GNP } \\
\left(10^{6} \text { US\$) }\right. \\
g_{i}\end{array}$} & \multirow{2}{*}{$\begin{array}{l}\text { Surface } \\
\left(1000 \mathrm{~km}^{2}\right) \\
s_{i}\end{array}$} & \multicolumn{2}{|c|}{ Cost coefficients } \\
\hline & & & & & & $\begin{array}{l}\text { Linear } \\
\alpha_{i}\end{array}$ & $\begin{array}{l}\text { Quadratic } \\
\beta_{i}\end{array}$ \\
\hline Albania & ALB & 25 & 78 & $\mathrm{NA}^{\mathrm{c}}$ & 29 & 1.25 & 0.026 \\
\hline Austria & AUS & 147 & 77 & 70640 & 84 & 1.00 & 0.02 \\
\hline Belgium & BEL & 306 & 67 & 109640 & 31 & 2.00 & 0.0095 \\
\hline Bulgaria & BUL & 500 & 83 & 37390 & 111 & 1.40 & 0.0021 \\
\hline Czechoslovakia & $\mathrm{CZE}$ & 1625 & 75 & 89260 & 128 & 1.00 & 0.000283 \\
\hline Denmark & DEN & 151 & 86 & 61520 & 43 & 1.80 & 0.0054 \\
\hline Finland & FIN & 180 & 85 & 46360 & 337 & 1.00 & 0.0175 \\
\hline France & FRA & 1015 & 76 & 601560 & 547 & 2.00 & 0.0054 \\
\hline German Dem. Rep. & GDR & 1300 & 80 & 120940 & 108 & 1.00 & 0.0005 \\
\hline Fed. Rep. Germany & FRG & 1375 & 86 & 758480 & 249 & 2.00 & 0.00056 \\
\hline Greece & GRE & 352 & 86 & 39910 & 132 & 0.831 & 0.0 \\
\hline Hungary & HUN & 825 & 77 & 20650 & 93 & 0.60 & 0.000389 \\
\hline Ireland & IRE & 70 & 82 & 16300 & 70 & 1.25 & 0.01 \\
\hline Italy & ITA & 1900 & 84 & 359210 & 301 & 1.05 & 0.0006 \\
\hline Luxembourg & LUX & 14 & 90 & 5400 & 3 & 7.00 & 0.6 \\
\hline Netherlands & NET & 170 & 87 & 155740 & 41 & 2.50 & 0.0076 \\
\hline Norway & NOR & 50 & 73 & 52410 & 324 & 1.75 & 0.14627 \\
\hline Poland & POL & 2050 & 63 & 139780 & 313 & 0.85 & 0.000849 \\
\hline Portugal & POR & 79 & 89 & 22430 & 92 & 1.35 & 0.006196 \\
\hline Romania & ROM & 100 & 83 & 50870 & 238 & 1.15 & 0.000543 \\
\hline Spain & SPA & 1638 & 82 & 195670 & 505 & 0.50 & 0.000668 \\
\hline Sweden & SWE & 165 & 76 & 114150 & 450 & 2.50 & 0.05927 \\
\hline Switzerland & SWI & 43 & 55 & 101440 & 41 & 2.00 & 0.07133 \\
\hline Turkey & TUR & 483 & 62 & 61610 & 461 & 1.25 & 0.000555 \\
\hline Soviet Union & USS & 6000 & 76 & 1212030 & 3364 & 1.30 & 0.000141 \\
\hline United Kingdom & UNK & 1845 & 81 & 467880 & 244 & 1.30 & 0.000193 \\
\hline Yugoslavia & YUG & 588 & 79 & 56660 & 256 & 1.25 & 0.000483 \\
\hline
\end{tabular}

a Adapted from Klaassen and Jansen (1989), and Maeler (1989).

b Iceland is excluded from the analysis, since its emissions and depositions do not affect and are not affected by any other European country.

c The 1980 GNP of Albania is extrapolated to be 3430 million US\$. 
grated model which has been developed to link emissions and depositions in Europe, to provide the necessary data. For our purpose RAINS provides, on the one hand, estimates of the cost functions associated with abatement by each of the 27 European countries considered, and, on the other hand, the effects in terms of deposition levels for various different abatement policies by these countries. A list of the 27 countries can be found in the first column of Table 1.

The information provided by RAINS can be used as input into an interactive multicriteria Decision Support System which serves to analyze the tradeoffs between various different policy scenarios, in terms of the cost and deposition levels for each country. In this system the effects of various different target levels for the deposition and abatement costs for each country can be explored in one single interactive computer session. In this session, the decision maker modifies the target levels at each stage as deemed appropriate, after which the computer model calculates a new recommended solution based upon these modified values.

Our approach differs from previous studies in that 1) benefits do not have to be expressed in terms of monetary units or utile values, 2) the abatement costs and depositions of each country can be considered separately, or alternatively groups of countries can be considered, 3) the analysis is interactive, so that various different scenarios and tradeoffs can be evaluated in a short period of time, and 4) the effects of limited transfers of funds between countries on emissions and depositions can easily be calculated. Such limited transfers are more reasonable in practice than transfers of large amounts of money. Therefore, the contribution of this paper is that it provides a modeling framework in which the relevant tradeoffs between depositions and abatement costs for each of the 27 European countries can be analyzed interactively. Thus, the model can serve as a decision support tool in the process of establishing international environmental policies.

The remainder of the paper is organized as follows. First, the background of the acid rain problem and the RAINS model are discussed, followed by a presentation of the formal model formulation and the multicriteria decision support method. Next, the method is illustrated by analyzing several scenarios and tradeoffs. Some extensions of our analysis and model formulation are suggested. The paper concludes with some final remarks.

\section{Background}

Recently, a growing body of literature on the policy aspects of acidification has developed (Watson, 1986). This research can be divided into several types. One approach is the multiattribute utility theory (MAUT) approach (Anandalingam, 1987) which analyzes feasible policy alternatives by establishing preference (utility) functions using either exact or imprecise preference information. A second type focuses on the costs and effects of certain specific emission reduction scenarios. For instance, Shaw et al. (1988) compare a nonabatement scenario (also called official energy scenario) with, among others, a uniform $30 \%$ reduction scenario by 1993 at the latest, which scenario was considered in the $\mathrm{SO}_{2}$ protocol of Helsinki 1985 (Hettelingh and Hordijk, 1986, p. 39). Shaw (1988) calculates costs associated with a uniform $50 \%$ emission reduction and shows how depositions could further be decreased by allocating the costs across countries in an optimal way in the sense that the total costs are minimized. This allocation of costs would involve a significant transfer of funds from Western European countries to Eastern European countries. Cesar and Klaassen (1990) estimate the deposition reductions and costs of the EC-directive (European Community, 1988) on large combustion plants. One drawback of the above studies is that no interactive mechanism is used to evaluate alternative deposition and abatement cost levels. This makes 'what-if' type analyses difficult, so that the tradeoffs between various scenarios cannot easily be evaluated. In addition, these papers often stress the advantages of coordinated international actions using major transfers of funds from West to East (Shaw, 1988). In reality, the scope of such transfers may be very limited.

A third type of research emphasizes the welfare economic analysis of acid rain abatement (Maeler, 1989; Van Ierland, 1989). The distinguishing characteristic of this research is that costs of emission reductions as well as benefits of the corresponding improvement of ecosystems, 
materials and buildings are assessed in monetary terms. In particular for the benefits this is a cumbersome and controversial task, because the diversity of benefit components are difficult to express monetarily, and because monetary benefits cannot easily be aggregated for all European countries. Maeler deals with this problem by assuming that marginal benefits are constant and that the cost functions and expenditures are known. Assuming rational governments, he assesses the appropriate levels of costs and benefits by equating marginal costs and benefits. The assumption of constant marginal benefits, however, is questionable. Van Ierland, on the other hand, uses an estimated piecewise linear benefit function for the Federal Republic of Germany (FRG). In order to simplify the problem, he subsequently assumes the shape and values of the benefit functions for all other countries to be the same as for the FRG. It is obvious that an analysis in which deposition reductions are expressed in physical terms is preferred to the approach in the above studies where benefit functions are estimated in either monetary values or utile values.

Another type of research focuses on policy implications, using either upper bounds or target values for the deposition levels in the various countries. Van Ierland (1989) deals with the ecologically oriented critical loads approach. The critical load represents the highest level of acidification for which no major damage is done to the ecosystem in the long run. Looking at both sulphur and nitrogen, Van Ierland selects a critical load level of 1400 acid equivalents per hectare, which in the case of sulphur only would translate into slightly over 2 grams per square meter. Klaassen and Jansen (1989) build a model using the political target approach. Concentrating on sulphur only, they take a target load of between 1 and 4 grams of sulphur per square meter. A target load can be interpreted as an attainable and politically acceptable load for the intermediate term, the ultimate goal of course being the achievement of the critical loads. Given these loads, the minimum costs and emission reductions needed to achieve these goals are calculated. As was the case with the previously mentioned type of research, however, a drawback of these studies is that there is neither an explicit balancing of the tradeoffs between abatement costs and the benefits of corresponding lower depositions across countries, nor a user-interactive tradeoff analysis.

This paper extends the above research by concentrating on an interactive abatement-deposition tradeoff analysis across 27 European countries. It is clear that such an analysis is of a multicriteria nature. The powerful and interactive nonlinear multicriteria optimization package IAC-DIDAS-N (Kreglewski et al., 1988), also known as DIDAS-N, is used to perform this analysis. The analysis is performed without making the controversial step of monetarizing the benefits. Additionally, the advantages of cooperative action are stressed because the tradeoff analysis clearly indicates which countries might transfer limited amounts of funds to other countries. At the same time, by selecting reasonable ranges for the acceptable deposition levels and costs in the tradeoff analysis, the resulting solutions are such that none of the countries is assumed or required to pay unreasonable sums of money to other countries, or to pay unreasonable domestic abatement costs. In contrast to MAUT (Anandalingam, 1987), our approach requires no a priori information from the policy makers in the form of a preference function, but explicitly and interactively presents the various feasible abatementdeposition tradeoffs to the policy makers for evaluation.

\section{The RAINS model}

RAINS is an integrated model of acidification in Europe which describes the set of relations that link the generation of pollutants with their depositions, and their adverse impacts on natural resources such as forests, groundwater and lakes. The emphasis of RAINS is on the transboundary aspects of air pollution (Alcamo et al., 1987). The model was developed at the International Institute for Applied Systems Analysis (IIASA) as a tool for evaluating control strategies. Currently the model is primarily sulphur-based, but nitrogen is presently being included and ammonia emissions may be included in the near future.

The parts of the model relevant for the purpose of this paper are: Energy Pathway, $\mathrm{SO}_{2}$ Emissions, $\mathrm{SO}_{2}$ Transport (including deposition), and $\mathrm{SO}_{2}$ Control and Abatement costs. In the Energy Pathway and $\mathrm{SO}_{2}$ Emissions Submodels, 
different energy projections can be implemented. The submodel accounts for five emission-producing sectors: conversion (e.g., refineries), power plants, domestic, industrial and transportation. Eight fuel types are distinguished: brown coal, hard coal, derived coal (e.g., coke, brown coal briquettes), light oil (e.g., gasoline), medium destillate (gas oil), heavy oil, gas and other fuels (Alcamo et al., 1987). The latter two are assumed to produce no sulphur emissions. Process emissions are taken into account as well when calculating the total emissions.

Energy conservation, fuel substitution, the use of lower-sulphur fuels and desulphurization are considered as means of emission reduction in the Pollution Control and Costs submodels of RAINS. Combustion modification, flue gas desulphurization and regenerative processes are considered as feasible technologies for desulphurization. Energy conservation is not yet included in the Costs submodel of RAINS. Costs are based on countryand technology-specific parameters (Amann et al., 1987; Amman, 1988). The resulting cost coefficients incorporate the most important factors influencing abatement costs of the European countries in an internationally comparable way. The cost functions are piecewise linear, reflecting that in order to reduce emissions further, another technique may have to be applied with higher marginal abatement costs.

The Transport submodel divides Europe into about $700150 \times 150$ kilometer grids, and predicts sulphur concentration and deposition due to $\mathrm{SO}_{2}$ emission patterns on each of these grids. In doing so, the submodel uses source-receptor linkages from the long-range atmospheric transport model developed by the Norwegian Meteorological Institute under the European Monitoring and Evaluation Program (EMEP) of the Economic Council of Europe (ECE) Convention on Transboundary Air Pollution. These source-receptor linkages combined determine the pollution transportation matrix.

In the following, a simplified and slightly modified version of RAINS due to Maeler (1989) is used. First, quadratic approximations are made of the stepwise linear cost functions of RAINS. Second, an aggregated $27 \times 27$ transportation matrix, representing the sulphur transport between 27 European countries, is used, rather than the 150 $\times 150$ kilometer grids in the full-blown RAINS model. An advantage of this aggregation is that the tradeoff analysis is more straightforward. A disadvantage, however, is that the deposition levels in the aggregate model represent country-wide averages, so that the deposition effects on different ecosystems within a country cannot be analyzed explicitly. The matrix used in our analysis differs slightly from that used by Maeler (see Stam et al., 1989). For a more detailed discussion of the drawbacks of the simplified version the reader is referred to Maeler (1989).

The output from the above submodels of RAINS serves as input for the decision support model in which the interactive tradeoff analysis is conducted. It is possible to evaluate multiple scenarios generated, using RAINS within the decision support framework. In Section 6, one such scenario based on Maeler (1989) is used.

\section{Model formulation}

To determine the tradeoffs between the deposition levels and abatement costs for each country, the transboundary relationships between $\mathrm{SO}_{2}$ emission, $\mathrm{SO}_{2}$ emission reduction, deposition and the associated abatement costs for each of the 27 countries can formally be stated as a nonlinear multicriteria mathematical programming problem. All cost figures, emission data and deposition data in the remainder of this paper have been calculated on an annual basis. Denoting the surface of country $i$ (in 1000 square kilometers) by $s_{i}$ and the deposition in country $i$ (in 1000 tons) by $d_{i}$, the decision problem for country $i$ is by how much it should reduce its emissions $\left(r_{i}\right)$ in such a way that both domestic abatement costs $c_{i}\left(r_{i}\right)$ and depositions in tons per square kilometer (or equivalently in grams per square meter) in country $i\left(d_{i} / s_{i}\right)$ are at an acceptable level. At the same time, depositions in country $i$ are affected by emission reductions in other countries. As, ceteris paribus, lower abatement costs and deposition levels are preferred to higher levels, the two criteria for country $i$ are to minimize $z_{i 1}=c_{i}\left(r_{i}\right)$ and $z_{i 2}=d_{i} / s_{i}$. Therefore, the aggregate problem has a total of $27 * 2=54$ separate criteria. Suppose we define the set of the 27 European countries as $S$. Then the mathematical 
formulation of the problem is as follows:

$$
\begin{array}{lll}
\text { Min } & z_{i 1}=c_{i}\left(r_{i}\right) & \text { for all } i \in S, \\
\text { Min } & z_{i 2}=d_{i} / s_{i} & \text { for all } i \in S, \\
\text { s.t. } & d_{i}=\sum_{j} a_{i j} *\left(e_{j}-r_{j}\right) & \text { for all } i \in S, \\
& 0 \leq r_{i} \leq m_{i} * e_{i} / 100 & \text { for all } i \in S,
\end{array}
$$

where $A=\left\{a_{i j}\right\}$ is the $27 \times 27 \mathrm{SO}_{2}$ transportation matrix between the different countries, such that $a_{i j}$ is the deposition in country $i$ as a proportion of $\mathrm{SO}_{2}$ emissions in country $j ; e_{i}$ represents the initial $\mathrm{SO}_{2}$ emission by country $i$ (in 1000 tons), i.e. the current emission level if a nonabatement strategy is adopted; and $m_{i}$ represents the maximum technologically feasible emission reduction for country $i$ as a precentage of $e_{i}$.

Maeler (1989, p. 14) indicates that the data on $m_{i}$ are based on information from IIASA. As mentioned before, following Maeler, quadratic abatement cost functions of the form $c_{i}\left(r_{i}\right)=\alpha_{i} r_{i}$ $+\beta_{i} r_{i}^{2}$ are used, where $\alpha_{i}$ and $\beta_{i}$ are scalar coefficients. The cost function estimates are based on the Energy Scenario 2000, and are expressed in million D-Mark. The emission and deposition data are based on 1984 energy consumption patterns (Maeler, 1989, p. 14). The GNP and surface figures were borrowed from Klaassen and Jansen (1989). The relevant numerical data for our illustration, in Section 6, are summarized in Table 1. The $\mathrm{SO}_{2}$ transportation matrix adapted from Maeler (1989) is not shown here but can be found in Stam et al. (1989).

In addition to the above model restrictions in (3) and (4), we will use policy target levels which seek to limit the abatement $\operatorname{costs} c_{i}\left(r_{i}\right)$ of country $i$ to a specific percentage $p_{i}$ of the annual 1980 GNP of country $i, g_{i}$. The reference point method upon which the multicriteria decision support package DIDAS-N is based, is well-suited for utilizing such policy target levels in the form of aspiration levels and reservation levels for each of the criteria. The DIDAS-N methodology is presented next.

\section{Multicriteria methodology}

The nonlinear multicriteria system DIDAS-N 3.2 (Kreglewski et al., 1988) can be run on an IBM/PC/XT/AT or compatible computer, as is the case with the RAINS model. DIDAS-N uses a user-friendly spreadsheet format, and facilitates an interactive decision process wich is based on the reference point method (Wierzbicki, 1982; Lewandowski and Wierzbicki, 1988a, 1988b). The methodology underlying DIDAS-N uses the concepts of satisficing solutions and bounded rationality (March and Simon, 1958), and has been shown to be consistent with the process of human decision making. The optimization module of DIDAS-N uses an order approximating achievement function with shifted penalties as the scalarizing function (Wierzbicki, 1982, 1986), and utilizes symbolic differentiation (Kreglewski et al., 1988), so that the user does not need to specify the derivatives of the objective function.

At each stage of the interactive process the decision maker can specify aspiration and reservation levels for the criteria. The aspiration level of a criterion represents the level which the decision maker would like to achieve, if possible, and the reservation level is the worst level acceptable to the decision maker. The aspiration and reservation levels are also called reference points. DIDAS-N uses these specified reference point values as the basis for solving a multicriteria optimization problem to find a Pareto-optimal or nondominated solution which reaches the aspiration levels of the criteria as closely as possible, while satisfying the reservation levels for the criteria, if possible. A solution is Pareto-optimal if none of the criteria can be improved without sacrificing at least one of the remaining criteria. A detailed discussion of the reference point method can be found in Wierzbicki (1982) or the user manual of DIDAS-N (Kreglewski et al., 1988). For other more general overviews of multicriteria decision making techniques and concepts the interested reader is referred to Steuer (1986) and Yu (1985).

At each iteration the solution which is calculated using the specified aspiration and reservation levels of the criteria is presented to the decision maker, who can subsequently modify these levels according to his/her preferences and the information contained in the solution. In this way (s)he is able to interactively explore various tradeoffs between the criteria. For instance, if the decision maker wishes to improve the deposition level in a given country, (s)he can lower the aspiration or reservation level for this criterion 
(or both), and within the ranges of all other criteria the model will attempt to find a solution which reaches the aspiration level as much as possible. At any point of the analysis the decision maker can inspect and evaluate the relevant decision variables on the screen. It is also possible to graphically display the tradeoffs between the criteria in the form of bar graphs.

Using the model formulation in (1)-(4), DIDAS- $\mathrm{N}$ first calculates the utopia and nadir values for the deposition and abatement cost criteria for each country. The utopia or selfish value of a criterion is its best possible value, ignoring all other criteria. Since the different criteria are conflicting, it is typically not possible to simultaneously attain the utopia values for all criteria. The nadir value of a criterion is defined by its worst possible value over the set of Pareto-optimal solutions. It is very difficult to calculate the exact nadir values (Isermann and Steuer, 1987), so that DIDAS-N approximates them by the worst criteria values calculated during the analysis. The utopia and nadir values provide important information to the decision maker, because they define the relevant range of criteria values which should be considered in the tradeoff analysis. For instance, if the utopia value for deposition in France equals 0.29 grams per square meter, then it is unreasonable - within the structure and underlying assumptions of the current model - to strive for deposition levels of less than 0.29 grams per square meter. An illustration of the methodology follows next.

\section{Illustration}

The utopia and nadir values for all 27 countries are given in Table 2. It is clear that the utopia value for abatement costs $c_{i}\left(r_{i}\right)$ equals zero for each country, because the lowest possible costs are associated with the nonabatement strat-

Table 2

Utopia, nadir values, aspiration, reservation values for the initial (neutral) solution for the unrestricted model, all 27 countries

\begin{tabular}{|c|c|c|c|c|c|c|c|c|c|c|}
\hline \multirow[t]{2}{*}{ Country } & \multicolumn{5}{|c|}{ Costs (million D-Mark) } & \multicolumn{5}{|c|}{ Depositions (grams $/ \mathrm{m}^{2}$ ) } \\
\hline & Utopia & Asp & Solution & Res & Nadir & Utopia & Asp & Solution & Res & Nadir \\
\hline ALB & 0 & 9.8 & 14.8 & 19.7 & 34.3 & 0.09 & 0.22 & 0.29 & 0.35 & 0.50 \\
\hline AUS & 0 & 89.4 & 134.1 & 178.8 & 369.4 & 0.54 & 1.10 & 1.38 & 1.66 & 2.37 \\
\hline BEL & 0 & 223.0 & 334.4 & 445.9 & 809.2 & 1.00 & 1.86 & 2.28 & 2.71 & 3.79 \\
\hline BUL & 0 & 298.2 & 447.3 & 596.5 & 942.7 & 0.29 & 0.67 & 0.87 & 1.06 & 1.59 \\
\hline CZE & 0 & 471.7 & 707.6 & 943.5 & 1639.5 & 1.37 & 2.65 & 3.30 & 3.94 & 5.40 \\
\hline DEN & 0 & 89.4 & 134.1 & 178.8 & 324.9 & 0.22 & 0.58 & 0.76 & 0.94 & 1.40 \\
\hline FIN & 0 & 134.5 & 201.8 & 169.0 & 562.7 & 0.08 & 0.16 & 0.21 & 0.25 & 0.38 \\
\hline FRA & 0 & 1094.3 & 1641.5 & 2188.7 & 4756.1 & 0.29 & 0.57 & 0.71 & 0.85 & 1.22 \\
\hline GDR & 0 & 130.0 & 195.0 & 260.0 & 540.8 & 1.10 & 2.24 & 2.81 & 3.39 & 5.22 \\
\hline FRG & 0 & 207.6 & 311.4 & 415.2 & 783.7 & 0.57 & 1.23 & 1.55 & 1.88 & 3.01 \\
\hline GRE & 0 & 82.0 & 123.1 & 164.1 & 251.5 & 0.15 & 0.41 & 0.55 & 0.68 & 0.94 \\
\hline HUN & 0 & 159.9 & 239.8 & 319.7 & 538.2 & 0.86 & 1.78 & 2.23 & 2.69 & 3.71 \\
\hline IRE & 0 & 30.7 & 46.0 & 61.3 & 104.7 & 0.09 & 0.23 & 0.29 & 0.36 & 0.50 \\
\hline ITA & 0 & 958.7 & 1438.1 & 1917.4 & 3204.1 & 0.45 & 1.06 & 1.36 & 1.67 & 2.56 \\
\hline LUX & 0 & 53.0 & 79.5 & 106.0 & 183.5 & 0.07 & 0.24 & 0.32 & 0.41 & 0.65 \\
\hline NET & 0 & 139.1 & 208.7 & 278.2 & 536.0 & 0.53 & 1.28 & 1.66 & 2.03 & 2.99 \\
\hline NOR & 0 & 52.2 & 78.4 & 104.5 & 258.7 & 0.06 & 0.11 & 0.13 & 0.15 & 0.23 \\
\hline POL & 0 & 681.3 & 1022.0 & 1362.7 & 2515.4 & 1.17 & 1.93 & 2.31 & 2.69 & 3.72 \\
\hline POR & 0 & 36.9 & 55.3 & 73.8 & 125.5 & 0.06 & 0.17 & 0.23 & 0.28 & 0.41 \\
\hline ROM & 0 & 25.1 & 37.7 & 50.2 & 99.2 & 0.27 & 0.53 & 0.67 & 0.80 & 1.09 \\
\hline SPA & 0 & 48.4 & 72.6 & 96.8 & 1876.3 & 0.20 & 0.48 & 0.62 & 0.76 & 1.12 \\
\hline SWE & 0 & 276.1 & 414.2 & 552.3 & 1245.5 & 0.11 & 0.20 & 0.24 & 0.29 & 0.42 \\
\hline SWI & 0 & 18.1 & 27.1 & 36.2 & 87.2 & 0.39 & 0.81 & 1.02 & 1.23 & 1.82 \\
\hline TUR & 0 & 132.6 & 198.8 & 265.1 & 424.2 & 0.15 & 0.24 & 0.28 & 0.33 & 0.43 \\
\hline USS & 0 & 3093.4 & 4640.1 & 6186.8 & 8859,9 & 0.22 & 0.42 & 0.51 & 0.61 & 0.92 \\
\hline UNK & 0 & 739.7 & 1109.5 & 1479.4 & 2373.0 & 0.44 & 1.03 & 1.33 & 1.62 & 2.28 \\
\hline YUG & 0 & 196.2 & 294.2 & 392.3 & 684.8 & 0.41 & 0.84 & 1.05 & 1.27 & 1.77 \\
\hline
\end{tabular}


egy $\left(r_{i}=0\right)$. On the other hand, the cost functions are convex, so that the nadir value for abatement costs $\left(c_{i}^{N}\right)$ is found by reducing domestic emissions to the maximum technologically feasible extent, implying $r_{i}=m_{i} * e_{i}$ and thus $c_{i}^{\mathrm{N}}\left(r_{i}\right)=$ $c_{i}\left(m_{i} * e_{i}\right)$. For instance, the maximum emission reduction for Ireland is $r_{\mathrm{IRE}}=0.82 * 70=57.4$ (see Table 1), so that its nadir cost value is $c_{\text {Ire }}^{\mathrm{N}}=1.25 * 57.4+0.01 *(57.4)^{2}=104.7$ million D-Mark. Similarly, the nadir value for deposition in each country is associated with the status quo of nonabatement, while the utopia value is reached if each country reduces emissions maximally. Again taking Ireland as an example, the $\mathrm{SO}_{2}$ transportation matrix (Maeler, 1989) shows that the deposition in Ireland consists of $24 \%$ of the emissions in Ireland plus one percent of the emissions in the United Kingdom, so that $d_{\mathrm{IRE}}=$ $0.24 * e_{\mathrm{IRE}}+0.01 * e_{\mathrm{UNK}}$. Nonabatement would imply $d_{\text {IRE }}=0.24 * 70+0.01 * 1845=35.25$, so that the deposition in grams per square meter is given by $d_{\text {IRE }} / s_{\text {IRE }}=(35.25) / 70=0.50$, while the maximum abatement strategy would yield $d_{\text {IRE }}$ $/ s_{\text {IRE }}=(0.24 *(1-0.82) * 70+0.01 *(1-0.81)$ $* 1845) / 70=0.09$. These values can also be found in Table 2. This table also shows the initial 'neutral' solution and associated initial aspiration (Asp) and reservation (Res) levels which DIDAS$\mathrm{N}$ suggests for each of the criteria as a reasonable starting point for the interactive decision process. The neutral solution can be interpreted as a 'middle-of-the-road' solution.

Inspecting Table 2, throughout Europe abatement costs are quite low compared to their nadir values. Most deposition levels are at a moderate level, with the exception of Belgium, Czechoslovakia, the German Democratic Republic (GDR), Hungary and Poland. These countries have a deposition level of more than 2 grams per square meter. The deposition of 3.30 grams in Czechoslovakia is particularly high, considering that this level represents a country-wide average, so that certain parts of the country will have much higher pollution levels. The model in Table 2 is called the 'unrestricted' model, because no 'hard' constraints are used to limit abatement costs and deposition levels.

As a first step to achieve deposition and cost levels within reasonable margins, the reservation levels suggested in the initial solution were uniformly changed to 2 grams per square meter for deposition and to $0.4 \%$ of GNP for abatement costs. None of the aspiration levels were changed. The GNP figures in Table 1 are in US dollars, and the cost functions are expressed in D-Marks. For the purpose of our analysis, the GNP data were converted to D-Marks using a conversion rate of $2.5 \mathrm{D}$-Mark for $1 \mathrm{US}$ dollar. Of course conversion rates fluctuate considerably, so that this rate is not exactly correct. In our paper the GNP data are only used for establishing reservation levels for abatement costs, so that a rough estimate of the conversion rate suffices. It is easy to repeat the analysis in our illustration using a different conversion rate, if this is desired. Since the reservation levels for all countries will be affected in the same proportion, the resulting solutions will likely be similar.

Simply stated, the reservation level of 2 grams for the average deposition within each country can be viewed as a pollution load, above which the ecosystem would be badly disturbed. The purpose of selecting these reservation levels is to study how this deposition level in one country can be reached by additional emission reduction measures in another country, especially if this one country already has high abatement costs. Note that for some countries such as Albania a target load of 2 grams is higher than the nadir value, so that these countries will always have deposition levels which are better (lower) than the 2 gram target load. The modified solution presented by DIDAS-N after changing the reservation levels is given in Table 3.

For several countries, the deposition and cost reservation levels cannot be met. In the case of Czechoslovakia, both the deposition and cost reservation levels are not met, but the nadir value for abatement costs is not yet reached, so the domestic depositions could be reduced further, albeit at great expense. Later we will address this issue in more detail. Countries such as Belgium, Hungary, the GDR and Poland, which had high deposition levels in the initial solution (see Table 2) now have greatly reduced deposition levels, but in the case of Poland at a cost exceeding the target level of $0.4 \%$ of GNP. In Table 3, Hungary has a reduced deposition level in spite of slightly lower domestic emission reductions than in the initial solution in Table 2. This is due to the increased emission abatement activities in surrounding countries. The reason why Hungary it- 
self does not spend additional funds on abatement is that the current level in Table 3, 222.2 million D-Mark, already exceeds its reservation level of $0.4 \%$ of GNP, 206.5 million D-Mark.

Interestingly, a number of Western European countries (e.g., FRG, Belgium, Denmark, France, Italy and the Netherlands) are at their nadir cost levels in Table 3, so that these countries are reducing their domestic emissions to the maximum feasible extent. The reason is that for these countries the $0.4 \%$ of GNP, used as the reservation level for abatement costs, far exceeds the nadir cost values. Thus, given the $0.4 \%$ reservation level it is reasonable to assume that these countries might be willing to transfer limited funds to other countries which have not yet reached their technological emission reduction limits, but have already exceeded their cost reservation levels.

As a further exercise, we divided Europe into Eastern Europe (the COMECON countries, Al- bania, Turkey and Yugoslavia) and Western Europe (The European Community, the Nordic countries, Austria and Switzerland). The deposition reservation levels for the Eastern European countries were kept at 2 grams per square meter, but for the Western countries these levels were tightened to 1 gram. At the same time, in order to obtain more realistic results, the reservation levels for abatement costs were lowered from $0.4 \%$ to $0.2 \%$ of GNP for Eastern Europe. The levels for the Western countries were kept at $0.4 \%$. The revised solution is given in Table 4 .

From this table we see that in four Eastern European countries (Czechoslovakia, Hungary, Poland and Yugoslavia) and in Luxembourg the cost targets are not met, and in addition the deposition level of 2 grams is not reached in Czechoslovakia and Hungary. Comparing Tables 3 and 4, we see that relaxing the reservation levels for abatement costs leads the Eastern European countries to spend less money on emis-

Table 3

Suggested solution with uniform reservation levels, unrestricted model

\begin{tabular}{|c|c|c|c|c|c|c|}
\hline \multirow[t]{2}{*}{ Country } & \multicolumn{3}{|c|}{ Costs (million D-Mark) } & \multicolumn{3}{|c|}{ Depositions (grams $/ \mathrm{m}^{2}$ ) } \\
\hline & Aspiration & Solution & Reservation & Aspiration & Solution & Reservation \\
\hline ALB & 0 & 0.0 & 34.3 & 0.09 & 0.46 & 2.00 \\
\hline AUS & 0 & 369.4 & 706.4 & 0.54 & 0.74 & 2.00 \\
\hline BEL & 0 & 809.2 & 1096.4 & 1.00 & 1.20 & 2.00 \\
\hline BUL & 0 & 173.6 & 373.9 & 0.29 & 1.21 & 2.00 \\
\hline $\mathrm{CZE}$ & 0 & $1211.2^{\mathrm{a}}$ & 892.6 & 1.37 & $2.17^{\mathrm{a}}$ & 2.00 \\
\hline DEN & 0 & 324.9 & 615.2 & 0.22 & 0.24 & 2.00 \\
\hline FIN & 0 & 0.0 & 463.6 & 0.08 & 0.31 & 2.00 \\
\hline FRA & 0 & 4756.1 & 6015.6 & 0.29 & 0.40 & 2.00 \\
\hline GDR & 0 & 540.8 & 1209.4 & 1.10 & 1.29 & 2.00 \\
\hline $\mathrm{FRG}$ & 0 & 783.7 & 7584.8 & 0.57 & 0.67 & 2.00 \\
\hline GRE & 0 & 0.0 & 399.1 & 0.15 & 0.88 & 2.00 \\
\hline HUN & 0 & $222.2^{a}$ & 206.5 & 0.86 & 1.95 & 2.00 \\
\hline IRE & 0 & 0.0 & 163.0 & 0.09 & 0.38 & 2.00 \\
\hline ITA & 0 & 3204.1 & 3592.1 & 0.45 & 0.51 & 2.00 \\
\hline LUX & 0 & 0.0 & 54.0 & 0.07 & 0.65 & 2.00 \\
\hline NET & 0 & 536.0 & 1557.4 & 0.53 & 0.68 & 2.00 \\
\hline NOR & 0 & 0.7 & 524.1 & 0.06 & 0.11 & 2.00 \\
\hline POL & 0 & $1540.6^{\mathrm{a}}$ & 1397.8 & 1.17 & 1.68 & 2.00 \\
\hline POR & 0 & 0.0 & 224.3 & 0.06 & 0.40 & 2.00 \\
\hline ROM & 0 & 99.2 & 508.7 & 0.27 & 0.50 & 2.00 \\
\hline SPA & 0 & 25.9 & 1956.7 & 0.20 & 1.03 & 2.00 \\
\hline SWE & 0 & 199.6 & 1141.5 & 0.11 & 0.20 & 2.00 \\
\hline SWI & 0 & 87.2 & 1014.4 & 0.39 & 0.39 & 2.00 \\
\hline TUR & 0 & 0.0 & 616.1 & 9.15 & 0.41 & 2.00 \\
\hline USS & 0 & 3267.4 & 12120.3 & 0.22 & 0.56 & 2.00 \\
\hline UNK & 0 & 1305.3 & 4678.8 & 0.44 & 1.15 & 2.00 \\
\hline YUG & 0 & 554.8 & 566.6 & 0.41 & 0.68 & 2.00 \\
\hline
\end{tabular}

${ }^{a}$ The reservation level could not be attained for this country, using the current scenario. 
sion reduction, and as a result depositions are generally higher in Table 4. On the other hand, many of the Western European countries were already spending relatively large amounts of money in the solution of Table 3 , and spend even more in that of Table 4, in order to reach the tighter deposition reservation level of 1 gram per square meter. A good example of this increased effort is the case of Luxembourg, which spends little money under the 2-gram scenario, but spends 123.4 million D-Mark in the 1-gram scenario. In fact, this additional expense is a sacrifice by Luxembourg to aid Belgium in reducing its deposition level from 1.20 in Table 4 to 1.0. Note that Belgium itself cannot spend more than it is already doing (809.2 million D-Mark). If such a sacrifice by Luxembourg is considered unreasonable, the model can easily be modified to set a limit to the sacrifice by Luxembourg. In our illustration this was not done. Alternatively, a limited transfer of money from Belgium to Luxembourg to compensate for the additional expense could be decided in international negotiations.

It is of interest to see whether it is possible (feasible) to impose a 'hard' restriction (upper bound) of at most 2 grams per square meter on the deposition level in each country. Such a hard restriction differs from a reservation level in that reservation levels do not have to be reached at any price, but no feasible solution exists if a 'hard' upper bound cannot be satisfied, and the mathematical program cannot be solved without relaxing some of these bounds. Table 5 gives the results from solving the revised model with uniform reservation levels of 2 grams for deposition and $0.4 \%$ of GNP for abatement costs. We call this the 'restricted' model because of the 'hard' constraints mentioned above.

Due to imposing the upper bounds, the utopia values for the criteria in Table 5 are slightly

Table 4

Suggested solution with different reservation levels for Eastern and Western Europe, unrestricted model

\begin{tabular}{|c|c|c|c|c|c|c|}
\hline \multirow[t]{2}{*}{ Country } & \multicolumn{3}{|c|}{ Costs (million D-Mark) } & \multicolumn{3}{|c|}{ Depositions (grams $/ \mathrm{m}^{2}$ ) } \\
\hline & Aspiration & Solution & Reservation & Aspiration & Solution & Reservation \\
\hline ALB & 0 & 12.0 & 17.2 & 0.09 & 0.38 & 2.00 \\
\hline AUS & 0 & 369.4 & 706.4 & 0.54 & 0.85 & 1.00 \\
\hline BEL & 0 & 809.2 & 1096.4 & 1.00 & 1.00 & 1.00 \\
\hline BUL & 0 & 96.2 & 187.0 & 0.29 & 1.34 & 2.00 \\
\hline $\mathrm{CZE}$ & 0 & $917.0^{a}$ & 446.3 & 1.37 & $2.67^{a}$ & 2.00 \\
\hline DEN & 0 & 324.9 & 615.2 & 0.22 & 0.24 & 1.00 \\
\hline FIN & 0 & 0.0 & 463.6 & 0.08 & 0.31 & 1.00 \\
\hline FRA & 0 & 4756.1 & 6015.6 & 0.29 & 0.35 & 1.00 \\
\hline GDR & 0 & 540.8 & 604.7 & 1.10 & 1.34 & 2.00 \\
\hline FRG & 0 & 783.7 & 7584.8 & 0.57 & 0.65 & 1.00 \\
\hline GRE & 0 & 78.9 & 399.1 & 0.15 & 0.71 & 1.00 \\
\hline HUN & 0 & $164.3^{\mathrm{a}}$ & 103.3 & 0.86 & $2.27^{\mathrm{a}}$ & 2.00 \\
\hline IRE & 0 & 0.0 & 163.0 & 0.09 & 0.29 & 1.00 \\
\hline ITA & 0 & 3204.1 & 3592.1 & 0.45 & 0.52 & 1.00 \\
\hline LUX & 0 & $123.4^{\mathrm{a}}$ & 54.0 & 0.07 & 0.20 & 1.00 \\
\hline NET & 0 & 536.0 & 1557.4 & 0.53 & 0.53 & 1.00 \\
\hline NOR & 0 & 0.0 & 524.1 & 0.06 & 0.09 & 1.00 \\
\hline POL & 0 & $1170.6^{a}$ & 698.9 & 1.17 & 1.91 & 2.00 \\
\hline POR & 0 & 98.8 & 224.3 & 0.06 & 0.21 & 1.00 \\
\hline ROM & 0 & 99.2 & 254.4 & 0.27 & 0.58 & 2.00 \\
\hline SPA & 0 & 205.2 & 1956.7 & 0.20 & 0.87 & 1.00 \\
\hline SWE & 0 & 225.6 & 1141.5 & 0.11 & 0.19 & 1.00 \\
\hline SWI & 0 & 87.2 & 1014.4 & 0.39 & 0.39 & 1.00 \\
\hline TUR & 0 & 0.1 & 308.1 & 0.15 & 0.41 & 2.00 \\
\hline USS & 0 & 3259.0 & 6060.2 & 0.22 & 0.57 & 2.00 \\
\hline UNK & 0 & 2373.0 & 4678.8 & 0.44 & 0.45 & 1.00 \\
\hline YUG & 0 & $413.6^{\mathrm{a}}$ & 283.3 & 0.41 & 0.83 & 2.00 \\
\hline
\end{tabular}

a The reservation level could not be attained for this country, using the current scenario. 
different from the previous tables. In particular, the lowest feasible abatement costs for Czechoslovakia, the GDR, Hungary and Poland are considerable. As expected, all deposition levels in the solution of Table 5 are now at most 2 grams per square meter, and Czechoslovakia is the only country which is exactly at this upper bound. Note that the surrounding countries are forced to major expenditures in order to force the deposition level in Czechoslovakia down to 2 grams. Czechoslovakia itself, however, is not spending more in the restricted solution of Table 5 than in its unrestricted counterpart of Table 4, because it was already spending considerably in excess of its reservation level of 892.6 million D-Mark. Similar to the situation described above for Luxembourg in Table 4, if it is deemed appropriate for Czechoslovakia to spend more on reducing its domestic emission (or if other countries agree to provide it with external funds to do so), either its abatement cost reservation level can be increased or a 'hard' lower bound on its abatement expenditures can be imposed.

The restricted model with 'hard' upper bounds of 2 grams for depositions in each country was also re-solved using the scenario of Table 4 with different reservation levels for Eastern (2 grams, $0.2 \%$ of GNP) and Western (1 gram, $0.4 \%$ of GNP) European countries. The results in Table 6 show that two countries, Belgium and Czechoslovakia, are exactly at the upper bound of their deposition level. Comparing Table 6 with Table 4 , we see that the deposition reduction from 2.67 to 2.0 grams in Czechoslovakia is in part due to a considerable abatement increase by Poland.

The above analyses show that a limited transfer of money from a country spending less than a given target amount to a country spending more might be reasonable. The extent of such transfers can be controlled by manipulating the aspiration and reservation levels for the criteria. These limited transfers are different from the transfers

Table 5

Suggested solution with uniform reservation levels for all 27 European countries, restricted model

\begin{tabular}{|c|c|c|c|c|c|c|}
\hline \multirow[t]{2}{*}{ Country } & \multicolumn{3}{|c|}{ Costs (million D-Mark) } & \multicolumn{3}{|c|}{ Depositions (grams $/ \mathrm{m}^{2}$ ) } \\
\hline & Aspiration & Solution & Reservation & Aspiration & Solution & Reservation \\
\hline ALB & 0 & 3.1 & 34.3 & 0.34 & 0.41 & 2.00 \\
\hline AUS & 0 & 369.4 & 706.4 & 0.69 & 0.74 & 2.00 \\
\hline $\mathrm{BEL}$ & 0 & 809.2 & 1096.4 & 1.04 & 1.18 & 2.00 \\
\hline BUL & 0 & 192.2 & 373.9 & 0.83 & 1.16 & 2.00 \\
\hline CZE & 1185.1 & $1185.1^{\mathrm{a}}$ & 892.6 & 1.63 & 2.00 & 2.00 \\
\hline DEN & 0 & 324.9 & 615.2 & 0.22 & 0.24 & 2.00 \\
\hline FIN & 0 & 92.5 & 463.6 & 0.24 & 0.24 & 2.00 \\
\hline FRA & 0 & 4502.9 & 6015.6 & 0.33 & 0.38 & 2.00 \\
\hline GDR & 210.3 & 540.8 & 1209.4 & 1.17 & 1.26 & 2.00 \\
\hline FRG & 0 & 783.7 & 7584.8 & 0.60 & 0.66 & 2.00 \\
\hline GRE & 0 & 79.0 & 399.1 & 0.61 & 0.67 & 2.00 \\
\hline HUN & 184.0 & $249.7^{\mathrm{a}}$ & 206.5 & 0.96 & 1.80 & 2.00 \\
\hline IRE & 0 & 2.1 & 163.0 & 0.15 & 0.36 & 2.00 \\
\hline ITA & 0 & 2556.7 & 3592.1 & 0.67 & 0.75 & 2.00 \\
\hline LUX & 0 & 9.0 & 54.0 & 0.07 & 0.60 & 2.00 \\
\hline NET & 0 & 536.0 & 1557.4 & 0.56 & 0.66 & 2.00 \\
\hline NOR & 0 & 2.6 & 524.1 & 0.09 & 0.09 & 2.00 \\
\hline POL & 581.6 & $2515.4^{\mathrm{a}}$ & 1397.8 & 1.26 & 1.30 & 2.00 \\
\hline POR & 0 & 0.1 & 224.3 & 0.30 & 0.33 & 2.00 \\
\hline ROM & 0 & 99.2 & 508.7 & 0.34 & 0.45 & 2.00 \\
\hline SPA & 0 & 708.8 & 1956.7 & 0.60 & 0.61 & 2.00 \\
\hline SWE & 0 & 95.9 & 1141.5 & 0.13 & 0.19 & 2.00 \\
\hline SWI & 0 & 87.2 & 1014.4 & 0.48 & 0.50 & 2.00 \\
\hline TUR & 0 & 96.0 & 616.1 & 0.33 & 0.35 & 2.00 \\
\hline USS & 0 & 4607.5 & 12120.3 & 0.46 & 0.46 & 2.00 \\
\hline UNK & 0 & 1478.3 & 4678.8 & 0.47 & 1.03 & 2.00 \\
\hline YUG & 0 & $684.8^{a}$ & 566.6 & 0.50 & 0.58 & 2.00 \\
\hline
\end{tabular}

a The reservation level could not be attained for this country, using the current scenario. 
Table 6

Suggested solution with different reservation levels for Eastern and Western Europe, restricted model

\begin{tabular}{|c|c|c|c|c|c|c|}
\hline \multirow[t]{2}{*}{ Country } & \multicolumn{3}{|c|}{ Costs (million D-Mark) } & \multicolumn{3}{|c|}{ Depositions (grams/m²) } \\
\hline & Aspiration & Solution & Reservation & Aspiration & Solution & Reservation \\
\hline ALB & 0 & 12.9 & 17.2 & 0.34 & 0.38 & 2.00 \\
\hline AUS & 0 & 369.4 & 706.4 & 0.69 & 0.69 & 1.00 \\
\hline BEL & 83.5 & 809.2 & 1096.4 & 1.04 & 1.00 & 1.00 \\
\hline BUL & 0 & $342.7^{\mathrm{a}}$ & 187.0 & 0.83 & 1.42 & 2.00 \\
\hline CZE & 1185.1 & $1207.1^{\mathrm{a}}$ & 446.3 & 1.63 & 2.00 & 2.00 \\
\hline $\mathrm{DEN}$ & 0 & 324.9 & 615.2 & 0.22 & 0.24 & 1.00 \\
\hline FIN & 0 & 34.3 & 463.6 & 0.24 & 0.27 & 1.00 \\
\hline FRA & 0 & 4706.1 & 6015.6 & 0.33 & 0.32 & 1.00 \\
\hline GDR & 210.3 & 540.8 & 604.7 & 1.17 & 1.21 & 2.00 \\
\hline FRG & 0 & 783.7 & 7584.8 & 0.60 & 0.60 & 1.00 \\
\hline GRE & 0 & 87.8 & 399.1 & 0.61 & 0.68 & 1.00 \\
\hline HUN & 184.0 & $195.1^{\mathrm{a}}$ & 103.3 & 0.96 & 1.97 & 2.00 \\
\hline IRE & 0 & 7.3 & 163.0 & 0.15 & 0.27 & 1.00 \\
\hline ITA & 0 & 3204.1 & 3592.1 & 0.67 & 0.48 & 1.00 \\
\hline LUX & 0 & 9.8 & 54.0 & 0.07 & 0.59 & 1.00 \\
\hline NET & 0 & 536.0 & 1557.4 & 0.56 & 0.53 & 1.00 \\
\hline NOR & 0 & 1.6 & 524.1 & 0.09 & 0.09 & 1.00 \\
\hline POL & 581.6 & $2515.4^{\mathrm{a}}$ & 698.9 & 1.26 & 1.28 & 2.00 \\
\hline POR & 0 & 16.5 & 224.3 & 0.30 & 0.30 & 1.00 \\
\hline ROM & 0 & 99.2 & 254.4 & 0.34 & 0.48 & 2.00 \\
\hline SPA & 0 & 689.6 & 1956.7 & 0.60 & 0.61 & 1.00 \\
\hline SWE & 0 & 59.2 & 1141.5 & 0.13 & 0.20 & 1.00 \\
\hline SWI & 0 & 87.2 & 1014.4 & 0.48 & 0.39 & 1.00 \\
\hline TUR & 0 & 49.4 & 308.1 & 0.33 & 0.38 & 2.00 \\
\hline USS & 0 & 4578.0 & 6060.2 & 0.46 & 0.46 & 2.00 \\
\hline UNK & 0 & 2334.6 & 4678.8 & 0.47 & 0.47 & 1.00 \\
\hline YUG & 0 & $684.8^{\mathrm{a}}$ & 283.3 & 0.50 & 0.57 & 2.00 \\
\hline
\end{tabular}

$\bar{a}$ The reservation level could not be attained for this country, using the current scenario.

proposed by Maeler (1989) and by Bergman et al. (1990), in that our solutions suggest only few countries (for instance, in the scenario of Table 6: Bulgaria, Czechoslovakia, Hungary, Poland and Yugoslavia) receive a payment and the amounts are much lower. The maximum transfer might be given by the difference between the reservation level and the actual solution value, e.g. Hungary might receive up to 91.8 million D-Mark. A drawback of our solutions is that abatements are not always done in the most cost-efficient way. On the other hand, the smaller transfers involved may render the solutions more realistic.

As a last case we study the situation where Belgium and the Netherlands want to limit depositions to at most 1 gram. For the remaining 25 countries, the aspiration and reservation levels suggested in the initial 'neutral' solution by DIDAS-N were used. The results for Belgium and the Netherlands from the initial 'neutral' solution for the unrestricted model in Table 2 are repeated in Table 7 . In this solution, the deposition

Table 7

Neutral solution for Belgium and the Netherlands, unrestricted model

\begin{tabular}{llllllll}
\hline Country & \multicolumn{2}{l}{ Costs (million D-Mark) } & & \multicolumn{3}{l}{ Depositions $\left(\mathrm{grams} / \mathrm{m}^{2}\right)$} \\
\cline { 2 - 3 } & Aspiration & Solution & Reservation & & Aspiration & Solution & Reservation \\
\hline BEL & 223.0 & 334.4 & 445.9 & & 1.86 & 2.28 & 2.71 \\
NET & 139.1 & 208.7 & 278.2 & & 1.28 & 1.66 & 2.03 \\
\hline
\end{tabular}


levels suggested by DIDAS-N for Belgium (2.28 grams) and the Netherlands (1.66 grams) are rather high, and the abatement costs are much below both the nadir values and the reservation level of $0.4 \%$ of GNP. Since in this section we want to focus on depositions, the aspiration and reservation levels for abatement costs were kept at the levels suggested by DIDAS-N in the initial solution. This implies that the aspiration levels for abatement costs will be impossible to attain, given our goal of lowering depositions.

From Table 8 we see that in the scenario where the aspiration and reservation levels for depositions in the Netherlands are set equal to 1 gram, both Belgium and the Netherlands spend more money on reducing emissions than in the 'neutral' solution: 550.2 million D-Mark versus 334.4 million for Belgium, and 391.4 million versus 208.7 million for the Netherlands. Both these cost figures are at a moderate level compared to their nadir values of 809.2 and 536.0 million DMark, respectively, but exceed the reservation levels. Table 9 shows the situation where the reservation level for deposition in Belgium is set equal to 1 gram.
As noted before, Belgium has difficulties achieving such a deposition level without help from other countries. This is shown by its very high domestic abatement costs, equal to the nadir value (809.2 million D-Mark). The Netherlands, on the other hand, helps Belgium by considerably reducing its emissions. The abatement costs to the Netherlands of 534.4 million D-Mark are quite high, and close to its nadir value of 536.0 million D-Mark. A reasonable conclusion is that perhaps Belgium might consider transferring a limited amount of money, not exceeding the differential effort by the Netherlands of 534.4 $391.4=143.0$ million D-Mark, if Belgium insists on limiting its depositions to 1 gram per square meter. On the other hand, the Netherlands benefit from their domestic abatement as well, reaching a deposition level of 0.53 grams as shown in Table 9, so that a transfer of close to 143 million D-Mark appears unreasonable. The extent of the monetary transfer (if any) might be decided in international negotiations. Finally, Table 10 shows the results of setting the reference values for both Belgium and the Netherlands equal to 1 gram. Since the Netherlands have no difficulty attaining

Table 8

Suggested solution for Belgium and the Netherlands, deposition reservation level in the Netherlands equal to one

\begin{tabular}{|c|c|c|c|c|c|c|}
\hline \multirow[t]{2}{*}{ Country } & \multicolumn{3}{|c|}{ Costs (million D-Mark) } & \multicolumn{3}{|c|}{ Depositions (grams $/ \mathrm{m}^{2}$ ) } \\
\hline & Aspiration & Solution & Reservation & Aspiration & Solution & Reservation \\
\hline BEL & 223.0 & 550.2 & 445.9 & 1.86 & 1.62 & 2.71 \\
\hline NET & 139.1 & 391.4 & 278.2 & 1.00 & 1.00 & 1.00 \\
\hline
\end{tabular}

Table 9

Suggested solution for Belgium and the Netherlands, deposition reservation level in Belgium equal to one

\begin{tabular}{|c|c|c|c|c|c|c|}
\hline \multirow[t]{2}{*}{ Country } & \multicolumn{3}{|c|}{ Costs (million D-Mark) } & \multicolumn{3}{|c|}{ Depositions (grams $/ \mathrm{m}^{2}$ ) } \\
\hline & Aspiration & Solution & Reservation & Aspiration & Solution & Reservation \\
\hline $\mathrm{BEL}$ & 223.0 & 809.2 & 445.9 & 1.00 & 1.00 & 1.00 \\
\hline NET & 139.1 & 534.6 & 278.2 & 0.13 & 0.53 & 2.03 \\
\hline
\end{tabular}

Table 10

Suggested solution for Belgium and the Netherlands, deposition reservation level for both equal to one

\begin{tabular}{|c|c|c|c|c|c|c|}
\hline \multirow[t]{2}{*}{ Country } & \multicolumn{3}{|c|}{ Costs (million D-Mark) } & \multicolumn{3}{|c|}{ Depositions (grams $/ \mathrm{m}^{2}$ ) } \\
\hline & Aspiration & Solution & Reservation & Aspiration & Solution & Reservation \\
\hline $\mathrm{BEL}$ & 223.0 & 809.2 & 445.9 & 1.00 & 1.00 & 1.00 \\
\hline NET & 139.1 & 521.6 & 278.2 & 1.00 & 0.54 & 1.00 \\
\hline
\end{tabular}


a deposition level below 1 gram, it is not surprising that the solution in Table 10 is very similar to that in Table 9.

\section{Extensions}

The current model formulation can be extended in a number of ways. First, it is possible to focus on individual countries other than the ones selected in our illustration. Second, the model can easily be reformulated to consider blocks of countries with aggregate cost functions. Two such blocks which may be of interest are on the one hand the European Community, and on the other hand the COMECON countries. Game-theoretic aspects of the model dynamics can be explored as well.

A straightforward extension of the current formulation is to include nitrogen emissions in the model, and to consider $\mathrm{Ph}$-levels rather than depositions due to $\mathrm{SO}_{2}$ emissions only. Such a model would involve a dynamic problem formulation, as the $\mathrm{Ph}$-levels of the soil depend in part on the $\mathrm{Ph}$-levels in the previous year. A pilot version of such a model formulation is already available as a demonstration problem on the DIDAS- $\mathrm{N}$ diskette (Kreglewski et al., 1988, pp. 38-41). This example problem is of limited size ( 2 regions and 3 years), and is a simplified version of the model formulation by Hettelingh and Hordijk (1986).

Another extension would be to utilize a finer grid of source-receptor linkages in the analysis. The analysis in our current paper is very rough, because only information on country-wide average depositions was used. A finer grid would enable studying the effects of pollution on different ecosystems within a country, and would enable the policy maker to establish tighter limits on those ecosystems which are particularly sensitive to pollution. It would also be of interest to investigate the computational limitations of the DIDAS-N system when finer grid models are analyzed

\section{Final remarks}

In this paper, a multicriteria framework was proposed to analyze tradeoffs between deposition levels and abatement costs within and across 27
European countries. Such a framework appears to have considerable advantages over previous single-objective approaches where total European costs are minimized given certain deposition targets, because the latter will likely call for unrealistically large transfers of money, whereas the multicriteria approach facilitates evaluating tradeoffs involving limited transfers between individual or small groups of countries. The illustration clearly shows that it is possible to investigate numerous different scenarios where the criteria levels for various countries are restricted, using either 'hard' constraints (upper bounds) or 'soft' target values (aspiration and reservation levels). Rather than comprehensively analyzing policy and strategy issues, our purpose in the current paper was to emphasize these possibilities. The task of analyzing the pros and cons of different scenarios associated with the acid rain problem in Europe is a very complicated one. Our proposed methodology provides a useful decision support tool to aid policy makers in analyzing this problem. Of course our paper constitutes only a first attempt towards designing a true decision support framework, and much work is yet to be done along the lines of the extensions mentioned above.

\section{Acknowledgement}

The authors thank Ger Klaassen and two other anonymous referees for their valuable comments. This paper was written in part while the authors were at the International Institute for Applied Systems Analysis in Laxenburg, Austria, as participants in the 1989 Young Scientist Summer Program. The authors are indebted to this organization for providing resources for this research.

\section{References}

Alcamo, J., Amann, M., Hettelingh, J.-P.. Holmberg, M. Hordijk, L., Kamari, J., Kauppi, L., Kauppi, P., Kornai, G., and Makela, A. (1987), "Acidification in Europe: A simulation model for evaluating control strategies", Ambio $16 / 5,232-245$

Amann, M. (1988), "Environmental impacts of different European energy strategies", presented at the IIASA/CVTU Workshop on Socioeconomic Impacts of Regional Integrated Energy Systems, Prague 
Amann, M., and Kornai, G. (1987), "Cost functions for controlling $\mathrm{SO}_{2}$ emission in Europe", WP-87-65, International Institute for Applied Systems Analysis, Laxenburg.

Anandalingam, G. (1987), "A multiple criteria decision analytic approach for evaluating acid rain policy choices", European Journal of Operational Reserach 29, 336-352.

Bergman, L., Cesar, H., and Klaassen, G. (1990), "A scheme for sharing the costs of reducing sulphur emissions in Europe", WP-90-005, International Institute for Applied Systems Analysis, Laxenburg.

Cesar, H., and Klaassen, G. (1990), "Costs, sulphur emission and depositions of the EC directive on large combustion plants", WP-90-006, International Institute for Applied Systems Analysis, Laxenburg.

European Community (1988), "Richtlijn van de Raad van november 1988 inzake beperking van de emissies van bepaalde verontreinigende stoffen in de lucht door grote stookinstallaties", Publikatieblad van de Europese Gemeenschappen, L.336/1, Brussels/Luxembourg (in Dutch).

Evelyn, J. (1661), "Fumifugium or the inconvenience of aer and smoake of London dissipated; together with some remedies humbly proposed", Essay offered to King Charles II, London.

Hettelingh, J.-P., and Hordijk, L. (1986), "Environmental conflicts: The case of acid rain in Europe", Annals of Regional Science 20, 38-52.

Isermann, H., and Steuer, R.E. (1987), "Computational experience concerning payoff tables and minimum criterion values over the efficient set", European Journal of Operational Research 33, 91-97.

Klaassen, G., and Jansen, H.M.A. (1989), "Economic principles for allocating the costs of reducing sulfur emissions in Europe", Working Paper, Institute for Environmental Studies, Amsterdam.

Kreglewski, T., Paczynski, J., Granat, J. and Wierzbicki, A.P. (1988), "IAC-DIDAS-N: A dynamic interactive decision analysis and support system for multicriteria analysis of nonlinear models", WP-88-112, International Institute for Applied Systems Analysis, Laxenburg.

Lewandowski, A., and Wierzbicki, A.P. (1988a), "Aspiration based decision analysis and support Part I: Theoretical and methodological backgrounds", WP-88-03, International Institute for Applied Systems Analysis, Laxenburg.

Lewandowski, A., and Wierzbicki, A.P. (1988b), "Theory, software and testing examples in decision support systems", WP-88-071, International Institute for Applied Systems Analysis, Laxenburg.

Maeler, K.-G. (1989), "The acid rain game", presented at the ESF Workshop on Economic Analysis for Environmental Toxicology, Amsterdam.

March, J., and Simon, H.A. (1958), Organizations, John Wiley, New York.

Shaw, R.W., Amann, M., and Schoepp, W. (1988), “The regional acidification information and simulation (RAINS) model - A tool to develop emission strategies and to assess their effects", presented at the European Conference on Combustion-Pollution-Reduction: New Techniques in Europe, Hamburg.

Shaw, R.W. (1988), "Transboundary acidification in Europe and the benefits of international cooperation", presented at the Conference on Pollution Knows no Frontiers: Priorities for Pan-European Cooperation, Varna.

Stam, A., Cesar, H., and Kuula, M. (1989), "Transboundary air pollution in Europe: An interactive multicriteria tradeoff analysis", WP-89-61, International Institute for Applied Systems Analysis, Laxenburg.

Steuer, R.E. (1986), Multiple Criteria Optimization: Theory, Computation and Application, John Wiley, New York.

Van Ierland, E. (1989), "The economics of transboundary air pollution in Europe", presented at the Conference on Environmetrics, Cairo.

Watson, S.R. (1986), "Modelling acid deposition for policy analysis", Journal of the Operational Research Society 37, 893-900.

Wierzbicki, A.P. (1982), “A mathematical basis for satisficing decision making", Mathematical Modelling 3, 391-405.

Wierzbicki, A.P. (1986), "On the completeness and constructiveness of parametric characterizations to vector optimization problems", OR Spektrum 8, 73-87.

Yu, P.-L. (1985), Multiple Criteria Decision Making: Concepts, Techniques, and Extensions, Plenum Press, New York. 
